Original Research Article

\title{
The Bethesda system for reporting of thyroid cytopathology and its category wise management
}

\author{
Varun Gupta ${ }^{1}$, Pooja Singh $^{2} *$
}

${ }^{1}$ Department of Pharmacology,

${ }^{2}$ Department of Pathology, Government Medical College Bharartpur, Rajasthan, India

Received: 01 August 2019

Revised: 13 September 2019

Accepted: 16 September 2019

\section{*Correspondence to:}

Dr. Pooja Singh,

Email: poojasingh7march@ yahoo.co.in

Copyright: (C) the author(s), publisher and licensee Medip Academy. This is an openaccess article distributed under the terms of the Creative Commons Attribution NonCommercial License, which permits unrestricted noncommercial use, distribution, and reproduction in any medium, provided the original work is properly cited.

\begin{abstract}
Background: Fine-needle aspiration cytology (FNAC) of thyroid is a rapid diagnostic test for thyroid nodules. The Bethesda system classifies thyroid FNAC into six categories. Each category is linked to a malignancy risk and has recommended clinical management. The aim of this study was to analyze the thyroid cytology smears by Bethesda system and to assess the frequency of various categories and to correlate it previous published studies. Category wise management is also discussed in detail.
\end{abstract}

Methods: A total of 388 thyroid FNAC samples were examined from January 2017 to June 2018 in the Department of Pathology, in Medanta- The Medicity Gurugram.

Results: A total of 388 cases were reported according to Bethesda system of reporting. Categories were as follows: I (14.69\%), II (61.85\%), III (11.34\%), IV $(2.57 \%), \mathrm{V}(2.660 \%)$, VI $(4.91 \%)$ nodules.

Conclusions: The Bethesda System for reporting thyroid cytopathology proved to be an excellent reporting system and it puts clinician and the cytopathologist on the same page and easier to communicate regarding diagnosis.

Keywords: Fine-needle aspiration cytology, Bethesda, Thyroid

\section{INTRODUCTION}

Fine needle aspiration (FNA) of thyroid was documented in the Martin and Alice paper of 1934 and further developed in papers by Tempka et al and Piaggio Blanco et al in 1948. ${ }^{1,2}$ FNAC is now recognized to be the first time investigation for a solitary thyroid nodule and has a valuable role in the diagnosis of the diffuse nontoxic goitre and can be used to confirm the diagnosis of clinically obvious malignancy. The thyroid weighs approximately 20 to 25 grams. It is a bilobed endocrine organ situated on either side of the trachea and oesophagus. The lobes are joined anteriorly by isthmus extending over the trachea. The gland produces thyroxine under the control of thyroid stimulating hormone secreted by the pituitary and also contains neuroendocrine cells which produce calcitonin.

Non-neoplastic lesions are more common in thyroid like goitre, thyroiditis and graves' disease. ${ }^{3}$ Neoplastic lesions like follicular neoplasms, papillary carcinoma, and medullary carcinoma though less common may show overlapping clinical features with non-neoplastic lesions.

FNAC is considered the gold standard diagnostic test in the evaluation of a thyroid nodule, and other tests like ultrasound and nuclear scan should be used in conjunction with FNAC. ${ }^{4}$ While it is easy to diagnose 
most benign and straightforward malignant lesions, diagnostic challenges arise when aspirates are quantitatively or qualitatively inadequate to exclude a neoplastic process. The Bethesda system for reporting thyroid cytopathology (TBSRTC) was introduced in 2007 to standardize terminology used in reporting thyroid cytology. The Bethesda system used six categories for thyroid cytology reporting, and each category is supplemented by a list of criteria. ${ }^{5}$

The six Bethesda categories are as below: ${ }^{6}$

\section{Non diagnostic (category I)}

Smears were considered as non-diagnostic when a thyroid FNA sample failed to fulfil the recommended criteria for adequacy which a minimum of 6 groups of well visualized (well stained, undistorted and unobstructed) follicular cells with at least ten cells per group, preferably on a single slide.

\section{Benign (category II)}

This category includes lesions like benign follicular nodule chronic lymphocytic thyroiditis.

\section{Follicular lesion of undetermined significance (category III)}

Smears that contain cells with architectural or nuclear atypia that is not sufficient to be classified as suspicious for a follicular neoplasm or suspicious for a malignancy.

\section{Follicular neoplasm or Suspicious for follicular neoplasm (category IV)}

Lesions were classified into this category if they were having high follicular cellularity with predominant microfollicle formations, scant colloid. Lesions exhibiting Hurthle cells were also included in this group.

\section{Suspicious for malignancy (category V)}

Lesions with some but not all the expected cytological features of malignancy are categorized as suspicious for malignancy and reported as category $\mathrm{V}$.

\section{Malignant (category VI)}

Malignant category includes papillary carcinoma and its variants medullary carcinoma poorly differentiated undifferentiated carcinoma squamous cell carcinoma metastatic tumors lymphomas and other related tumors.

\section{$\operatorname{Aim}$}

This study aims to study the spectrum of various thyroid FNAC samples based on Bethesda system of thyroid cytopathology reporting. The treatment plan of various Bethesda categories is also discussed in brief.

\section{METHODS}

In this retrospective observational study, a total of 388 thyroid FNAC samples were examined from January 2017 to June 2018. The study was done in the Department of Pathology, in Medanta- The Medicity Gurugram. For cytomorphological analysis, all smears (papanicolaou and MGG) were reviewed and cases were categorized into six Bethesda categories. Relevant clinical information such as patient age, gender, and clinical presentation and other information such as FNAC, ultrasound, and surgical findings were obtained from LIS system and correlated accordingly.

\section{Inclusion criteria}

All the patients with age of 3-80 years with palpable thyroid swellings as well as USG guided samples and no signs of acute inflammation were included in the study.

\section{Exclusion criteria}

All other neck swellings other than thyroid. Acute thyroiditis i.e., tender, soft in consistency with signs of inflammation or cellulitis of neck region were excluded from the study.

The data obtained were statistically analyzed by SPSS software version 23 .

\section{RESULTS}

A total of 388 cases were reported according to Bethesda system of reporting. Category II is the most common lesion amounting to about $61.85 \%$ of total cases followed by category I (14.69\%) and category III (11.34\%) (Figure 1).

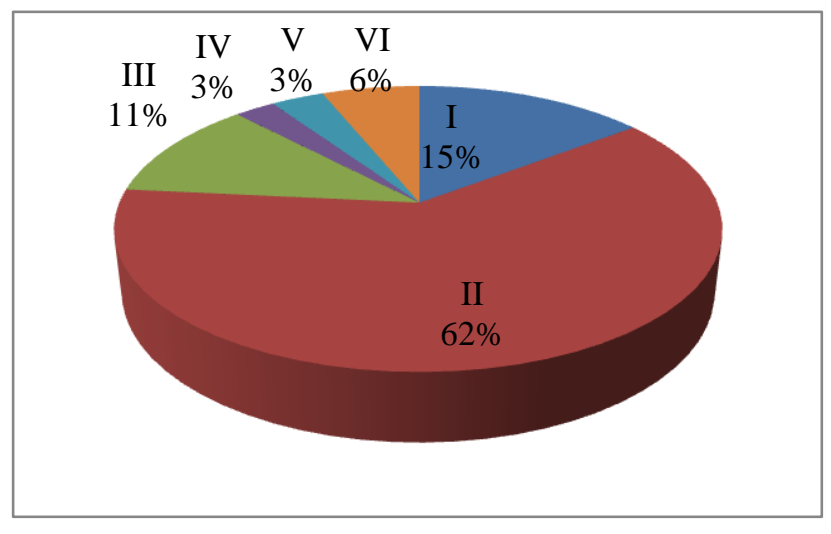

Figure 1: Distribution of thyroid lesions according to Bethesda system.

Category II lesions included predominantly colloid nodule followed by adenomatoid nodule with 
multinodular goitre being the third common as observed while reporting. Exact number could not be obtained as we now report only according to Bethesda system. Lymphocytic thyroiditis was found to be the forth common lesion. Category I included hemorrhagic smears inadequate samples, reactive lymph nodes and a necrotizing lesion suggestive of tuberculosis as well. One cystic lesion and a thyroglossal cyst were also reported in category I. Category III included lesions with occasional microfollicles, low cellularity or microfollicles like arrangement. Category IV included follicular neoplasms with definite microfollices and adequate cellularity. Category V and VI mainly included papillary carcinoma, 2 cases of metastatic carcinoma and 1 case of poorly differentiated carcinoma. A female preponderance was noted in our study with $268(69.07 \%)$ cases.

Table 1: Distribution of cases as per TBSRTC.

\begin{tabular}{|llllll|l|}
\hline $\mathbf{I}$ & II & III & IV & V & VI & Total \\
\hline $\mathbf{N}(\boldsymbol{\%})$ & $\mathbf{N}(\boldsymbol{\%})$ & $\mathbf{N}(\boldsymbol{\%})$ & $\mathbf{N}(\boldsymbol{\%})$ & $\mathbf{N}(\boldsymbol{\%})$ & $\mathbf{N}(\boldsymbol{\%})$ & \\
\hline $57(14.69)$ & $240(61.85)$ & $44(11.34)$ & $10(2.57)$ & $13(2.66)$ & $24(4.91)$ & 388 \\
\hline
\end{tabular}

\section{Management of various Bethesda categories of thyroid lesions}

The usual management for category I was repeat FNA under ultrasound guidance while for the most common category- benign, clinical follow up is advised. Treatment for Hashimoto's thyroiditis should begin with thyroid hormone replacement with levothyroxine which prevents or corrects the hypothyroidism. Treatment for De Quervain's thyroiditis is usually bed rest and aspirin to reduce inflammation. Occasionally cortisone (steroids, which reduce inflammation) and thyroid hormone (to "rest" the thyroid gland) may be used in prolonged cases. ${ }^{7}$

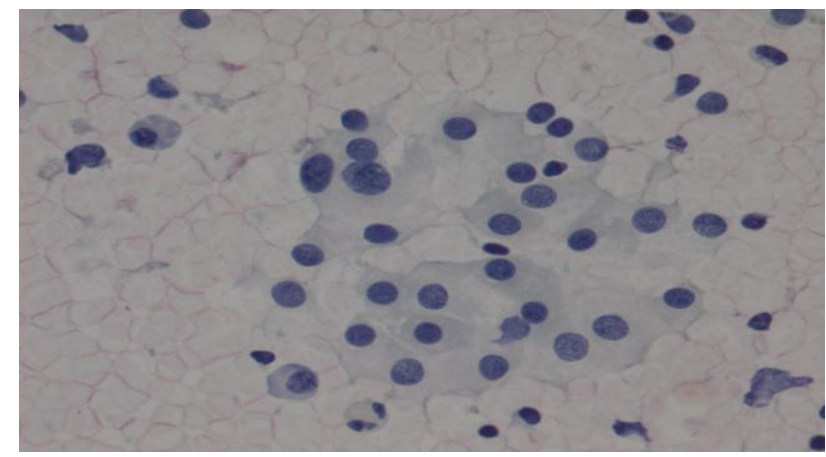

Figure 2: 400X, Papanicolau stain, Hurthle cells in a case of Hashimoto's thyroiditis, category II.

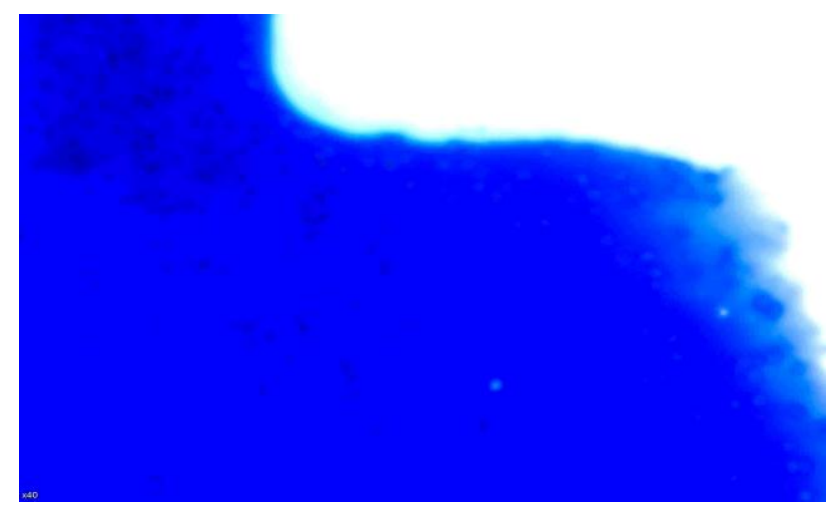

Figure 3: 400X, Giemsa stain, colloid with few entrapped normal follicular cells in a colloid nodule, category II.
The controversial area in Bethesda classification is newly introduced category III i.e., atypia of undetermined significance. It represents heterogeneous group of FNAC patterns where definitive diagnosis cannot be given. Ideally cases of AUS need a close follow up with a repeat FNA after 3 months as per Bethesda recommendations whereas near total or total thyroidectomy is recommended for category $\mathrm{V}$ and VI.

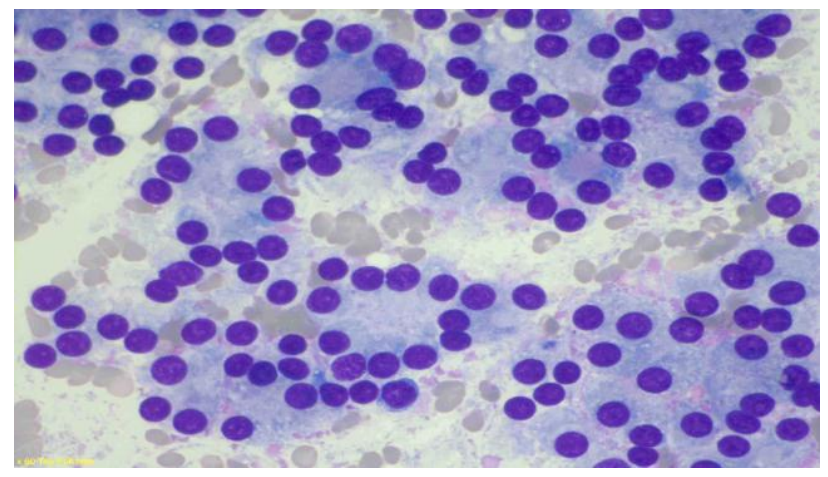

Figure 4: 400X, Giemsa stain, highly cellular smears showing microfollicular arrangement, follicular thyroid neoplasm, category IV.

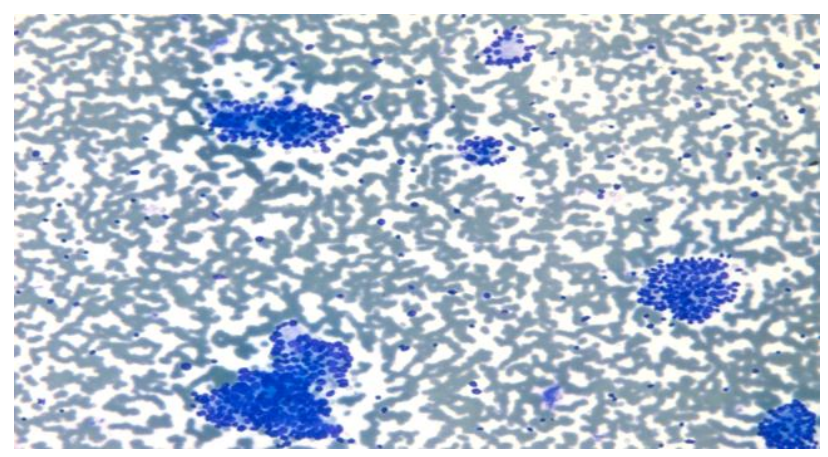

Figure 5: 100X, Giemsa stain, highly cellular smears with papillary clusters showing peripheral palisading, papillary carcinoma, category VI.

\section{DISCUSSION}

Around $69.07 \%$ cases were females in our study. Similar female preponderance was noted by Unnikrishnan et al in 
their study too. ${ }^{8}$ The FNAC lesions of thyroid were originally reported in Bethesda system of reporting and categorized as six categories as summed up in Table 1 (14.69\%), II (61.85\%), III (11.34\%), IV (2.57\%), V $(2.660 \%)$, VI $(4.91 \%)$. This data was corroboratory to the results of study conducted by Jo et al. ${ }^{9}$ Jo et al conducted study of 3,080 thyroid FNA samples from 1992 to 2009, at the University of Virginia Health System, Charlottesville, and classified thyroid lesions according to TBSRTC. Of the 3,080 FNAC samples, $18.6 \%$ were found to be non-diagnostic, $59.0 \%$ were benign, $3.4 \%$ were atypical follicular lesion of undetermined significance (AFLUS), 9.7\% were "suspicious" for follicular neoplasm (SFN), 2.3\% were suspicious for malignancy, and $7.0 \%$ were malignant. ${ }^{8}$ Category II is the most common in both the studies followed by category I.

\section{CONCLUSION}

It correlates cytological diagnosis with biological behavior and increasingly conservative patient management. The new category of AUS or FLUS in TBSRTC includes a subset of lesions not easily classified as benign, suspicious or malignant, while SFN category is reserved for specimens suspicious of follicular carcinoma. Based on TBSRTC and supported by many studies, AUS or FLUS cases are found to have a lower malignancy risk on surgical follow-up than patients with an initial diagnosis of SFN on cytology, highlighting the importance of such distinction. Positive or malignant category is reserved for high-grade, aggressive malignancies like papillary carcinoma, medullary carcinoma, lymphomas, squamous carcinoma etc. The Bethesda System for reporting thyroid cytopathology (TBSRTC) reporting of puts clinician and the cytopathologist on the same page and easier to communicate regarding diagnosis.

Funding: No funding sources Conflict of interest: None declared

Ethical approval: The study was approved by the Institutional Ethics Committee

\section{REFERENCES}

1. Martin HE, Ellis EB. Aspiration biopsy. Surg Gynaecol Obstet. 1934;59:578-89.

2. Grunze H, Spriggs AI. History of clinical cytology: a selection of documents. 2nd ed. Darmstadt:G-I-T Verlag Ernst Giebelet; 1983: 132.

3. Dash M, Chandrasekhar KPA, Raghu K, Saadvi K. Histopathological study of neoplastic and nonneoplastic thyroid lesions: an institutional experience of 2 years. J Evol Med Dent Sci. 2016;5(73):5348-51.

4. Gupta M, Gupta S, Gupta VB. Correlation of fine needle aspiration cytology with histopathology in the diagnosis of solitary thyroid nodule. J Thyroid Res. 2010;2010:379051.

5. Melo-Uribe MA, Sanabria A, Romero-Rojas A, Perez G, Vargas EJ, Abaunza MC, et al. The Bethesda system for reporting thyroid cytopathology in Colombia: Correlation with histopathological diagnoses in oncology and non-oncology institutions. J Cytol. 2015;32:12-6.

6. Cibas ES, Ali SZ. The Bethesda system for reporting thyroid cytopathology. Am J Clin Pathol. 2009;132:658-65.

7. Bindra A, Braunstein GD. Thyroiditis. Am Fam Physician. 2006; 73(10):1769-76.

8. Unnikrishnan AG, Kalra S, Baruah M. Endocrine society of India management guidelines for patients with thyroid nodules: A position statement. Indian J Endol Metab. 2011;15:2-8.

9. Jo VY, Stelow EB, Dustin SM, Hanley KZ. Malignancy risk for fine-needle aspiration of thyroid lesions according to the Bethesda system for reporting thyroid cytopathololy. Am J Clin Pathol. 2010;134:450-6.

Cite this article as: Gupta V, Singh P. The Bethesda system for reporting of thyroid cytopathology and its category wise management. Int J Basic Clin Pharmacol 2019;8:2228-31. 